\title{
Rupture of posterior cruciate ligament leads to radial displacement of the medial meniscus
}

\author{
Can Zhang ${ }^{\dagger}$, Zhenhan Deng ${ }^{\dagger}$, Wei Luo, Wenfeng Xiao, Yihe Hu, Zhan Liao, Kanghua Li ${ }^{*}$ and Hongbo He*
}

\begin{abstract}
Background: To explore the association between the rupture of posterior cruciate ligament $(\mathrm{PCL})$ and the radial displacement of medial meniscus under the conditions of different flexion and various axial loads.

Methods: The radial displacement value of medial meniscus was measured for the specimens of normal adult knee joints, including 12 intact PCLs, 6 ruptures of the anterolateral bundle (ALB), 6 ruptures of the postmedial bundle (PMB), and 12 complete ruptures. The measurement was conducted at $0^{\circ}, 30^{\circ}, 60^{\circ}$, and $90^{\circ}$ of knee flexion angles under $200 \mathrm{~N}, 400 \mathrm{~N}, 600 \mathrm{~N}, 800 \mathrm{~N}$ and $1000 \mathrm{~N}$ of axial loads respectively.

Results: The displacement values of medial meniscus of the ALB rupture group increased at $0^{\circ}$ flexion under $800 \mathrm{~N}$ and $1000 \mathrm{~N}$, and at $30^{\circ}, 60^{\circ}$ and $90^{\circ}$ flexion under all loads in comparison with the PCL intact group. The displacement values of the PMB rupture group was higher at $0^{\circ}$ and $90^{\circ}$ flexion under all loads, and at $30^{\circ}$ and $60^{\circ}$ flexion under $800 \mathrm{~N}$ and $1000 \mathrm{~N}$ loads. The displacement of the PCL complete rupture group increased at all flexion angles under all loads.

Conclusions: Either partial or complete rupture of the PCL can increase in the radial displacement of the medial meniscus, which may explain the degenerative changes that occuring in the medial meniscus due to PCL injury. Therefore, early reestablishment of the $P C L$ is necessarily required in order to maintain stability of the knee joint after $P C L$ injury.
\end{abstract}

Keywords: PCL rupture, Medial meniscus, Radial displacement

\section{Background}

The menisci are two crescent-shaped fibrocartilage structures located on the joint surface of the medial and lateral tibial plateau. The triangular cross sections of the menisci, which are slightly concave above and flat below, form a deep depression on the tibial plateau so that the ball-shaped femur condyle can be well accommodated [1]. The meniscus plays an important role in the mechanisms of load bearing, load transmission and shock absorption, and is also crucial to the lubrication and nutrition of articular cartilage [2]. Displacement of the meniscus to the periphery radially is referred to as "radial displacement of the meniscus" or "meniscal

\footnotetext{
* Correspondence: Ikh8708@sina.com; xiangyahehongbo@163.com ${ }^{\dagger}$ Equal contributors

Department of Orthopaedics, Xiangya Hospital, Central South University, No.87 Xiangya Road, Changsha, Hunan 410008, China
}

subluxation" or "meniscal extrusion" This phenomenon is commonly observed through magnetic resonance imaging (MRI) and ultrasound examinations [3-5]. Radial displacement may be linked to a reduction in meniscal function and other disorders of the knee. Recently, researches have been done to study the radial displacement of the medial meniscus [6-10], the incidence of which increases with osteoarthritis (OA) progression. Radial displacement of the medial meniscus also occurs as a complication upon the completion of meniscal transplantation $[9,10]$. However, the association between the rupture of posterior cruciate ligament (PCL) rupture and the meniscus displacement has not been clearly elaborated.

The PCL is an important structure that helps to ensure maintain the stability of the knee joint and to prevent the posterior displacement of the tibia [11]. A number of studies have been conducted to examine the 
effects of PCL injury on the biomechanics of the knee joint $[12,13]$, but the clinical and biomechanical researches that had been launched on the relationship between PCL injuries and the menisci was very limited [14-16]. We have performed a cadaveric study previously to investigate the biomechanics of how partial and complete PCL ruptures affect the lateral meniscus displacement at various flexion angles under different axial loads, and found that even partial PCL rupture could initiate lateral meniscus displacement, which became more obvious at larger flexion angles and greater loads. [17]. As part of our PCL and meniscus research series, a biomechanical testing system was applied to record the radial displacement of the medial meniscus under three different conditions, namely the anterolateral bundle (ALB) rupture, the posteromedial bundle (PMB) rupture and the PCL complete rupture. The objective of the present study was to examine the impact of PCL rupture on the radial displacement of the medial meniscus by biomechanical testing, for various flexion angles and different axial loads.

\section{Methods}

\section{Subjects}

The experiment of the present study had obtained approval from the Medical Ethics Committee of Xiangya Hospital, Central South University (Grant number: 201,212,062). As described previously [17], a total of 12 fresh human knees were collected from 6 human cadavers (average age of subject: 30.6 years, ranging from 25 to 38 years) and used as specimens. The deaths of the subjects were caused by accidents or other reasons that did not affect the normal structure and function of the knee. The donors' family had been informed of the objective of the present research and had signed a consent form for the relevant experiment and publication. Macroscopic inspections and radiological examinations were performed to rule out fractures, tumors, severe osteoporosis, degenerative joint disease and other anomalies. The posterior drawer test was used to exclude specimens with PCL damage. Each whole knee was cut off with a section of $30 \mathrm{~cm}$ reserved for both the femoral and tibial side, keeping the skin and soft tissue intact. The specimens were covered by the sterile gauze soaked in normal saline (NS) and then sealed in double plastic bags. All the specimens were stored at $-70{ }^{\circ} \mathrm{C}$, and the length of the low-temperature storage time was no more than 3 months.

\section{Group of experiments and test procedures}

As described previously [17], the specimens were grouped into four sets following the sequence in which the experiments were conducted: the PCL intact group $(n=12)$, the ALB rupture group $(n=6)$, the PMB rupture group $(n=6)$ and thePCL complete rupture group $(n=12)$. The sample size was calculated using an online sample size calculator which indicated that the sample size was suitable to detect a difference between treatments.

The specimens were thawed before conducting the experiments, and the soft tissues at the end of the femur and tibia were removed, leaving ones around the knee joint intact. Then, both the ends of the femur and tibia were fixed in a cylinder, ensuring that the specimens were firmly settled during the test. Subsequently, the cadaveric knees were fixed onto the cylindrical clamps of a universal testing machine (CSS-88100, ChangChun, China), with the femur side fixed on the top and the tibia side at the bottom. During the testing process, the knee was in extension and postured with a $10^{\circ}$ valgus angle from the vertical axis, which was to simulate the $10^{\circ}$ valgus angle of a normal knee. The quadriceps was fixed to the femur using wires with a tension of $100 \mathrm{~N}$. The posterior articular capsule was cut through a posterior midline incision in order to expose but not to cut off the PCL. The middle point of the medial margin of the medial meniscus was exposed through a medial longitudinal incision. After removing the surrounding soft tissues and the those in the medial margin of the tibial plateau, a $200 \mathrm{~N}$ load was imposed to the specimens with the speed of $0.5 \mathrm{~mm} / \mathrm{s}$. This procedure was repeated 20 times to eliminate the innate viscosity of the specimens.

Balance calibration was performed to the static strain measuring device before the testing. Then experiments were conducted at $0^{\circ}, 30^{\circ}, 60^{\circ}$ and $90^{\circ}$ of flexion respectively for the specimens (Fig. 1). A continuouslyincreasing axial load $(0-1000 \mathrm{~N})$ was imposed with the speed of $0.5 \mathrm{~mm} / \mathrm{s}$. The elasticity of the specimens was restored at 10-min intervals. The radial displacement of the medial meniscus was defined as the distance from the midpoint of the peripheral margin of the medial meniscus to the midpoint of the edge of the medial tibial plateau. This distance was measured by a digital caliper under $200 \mathrm{~N}, 400 \mathrm{~N}, 600 \mathrm{~N}, 800 \mathrm{~N}$ and $1000 \mathrm{~N}$ loads respectively. After that, a static strain measuring device was engaged to record the static strain in every channel under the desired conditions. When the aforementioned procedure was complete, the specimens were randomly divided into the ALB rupture group $(n=6$, where the ALB was transected) and the PMB rupture group $(n=6$, where the PMB was transected). The test procedure described above was repeated for these two groups. Lastly, the PCL was transected for all the 12 specimens in order to create the PCL complete rupture group, and the same test procedure was performed. During the whole experiment, the specimens were maintained at an appropriate and stable level of humidity and temperature. 

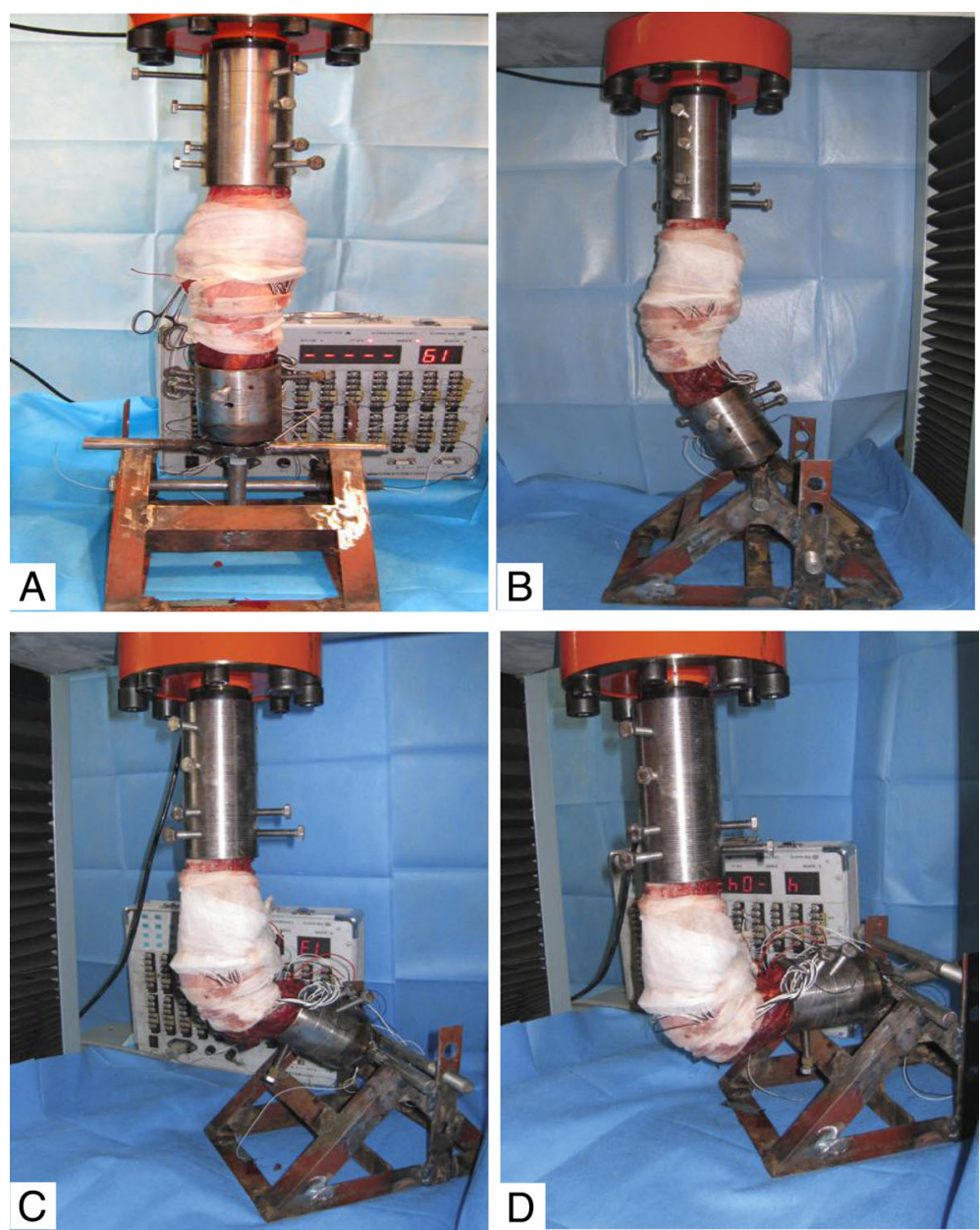

Fig. 1 Fixation of knee specimens for biomechanical testing at $0^{\circ}(\mathbf{a}), 30^{\circ}(\mathbf{b}), 60^{\circ}(\mathbf{c})$ and $90^{\circ}(\mathbf{d})$ of flexion

\section{Statistical analysis}

All the data are available in the text. The software SPSS 16.0 (version 15.0 for Windows; SPSS Inc., Chicago, IL, USA) was applied for statistical analysis and management. The data were expressed as the mean $\pm \mathrm{SD}$. The one-way analysis of variance (ANOVA), SNK-q and Dunnett's T3 were applied respectively multi-sample means comparisons, heterogeneity of variance. Any difference with $P<0.05$ was considered as statistically significant.

\section{Results}

Table 1 presents the radial displacements of the medial meniscus of all groups at different knee flexion angles under the various loading conditions. When compared with the PCL intact group, the displacement of the ALB rupture group was higher under the load of $800 \mathrm{~N}$ and $1000 \mathrm{~N}(P<0.05)$. In the PMB rupture and PCL complete rupture groups, the displacement was higher under all loads $(P<0.05)$. In comparison with the with the ALB rupture group, the displacement increased significantly in the PMB rupture and PCL rupture groups under all loads $(P<0.05)$. However, in comparison with the PMB rupture group, the displacement of the PCL complete rupture group increased significantly under the load of $200 \mathrm{~N}, 400 \mathrm{~N}$ and $600 \mathrm{~N}(P<0.05)$, but whereas showed no significant increases under the load of $800 \mathrm{~N}$ and $1000 \mathrm{~N}(P>0.05)$.

At $30^{\circ}$ of flexion, the displacement of the ALB rupture group and the PCL complete rupture group was significantly higher than that of the PCL intact group under all loads $(P<0.05)$. In the PMB rupture group, the displacement increased markedly under the load of $800 \mathrm{~N}$ and $1000 \mathrm{~N}(P<0.05)$, but showed no significant elevation under other loading conditions $(P>0.05)$. The displacement of the PMB rupture group differed significantly from that of the ALB rupture group under all loads, and the displacement of the PCL complete rupture group differed significantly from the ALB rupture group under the load of $800 \mathrm{~N}$ and $1000 \mathrm{~N}(P<0.05)$. In comparison with the PMB rupture group, the displacement of the PCL complete rupture group increased significantly under all loads $(P<0.05)$. 
Table 1 The radial displacement of medial meniscus at different flexion angles under various loads for all groups (means \& SD, mm)

\begin{tabular}{|c|c|c|c|c|c|c|}
\hline \multirow[t]{2}{*}{ Flexion angels } & \multirow[t]{2}{*}{ Groups } & \multicolumn{5}{|l|}{ Loading conditions } \\
\hline & & $200 \mathrm{~N}$ & $400 \mathrm{~N}$ & $600 \mathrm{~N}$ & $800 \mathrm{~N}$ & $1000 \mathrm{~N}$ \\
\hline \multirow[t]{4}{*}{$0^{\circ}$} & PCL intact group & $1.18(0.12)$ & $1.19(0.14)$ & $1.26(0.19)$ & $1.41(0.19)$ & $1.57(0.20)$ \\
\hline & ALB rupture group & $1.22(0.18)$ & $1.31(0.11)$ & $1.47(0.19)$ & $2.09(0.18)^{a}$ & $2.29(0.18)^{a}$ \\
\hline & PMB rupture group & $2.05(0.13)^{a, b}$ & $2.27(0.11)^{a, b}$ & $2.81(0.11)^{a, b}$ & $3.36(0.12)^{a, b}$ & $3.57(0.17)^{a, b}$ \\
\hline & PCL rupture group & $2.16(0.18)^{a, b}$ & $2.35(0.22)^{a, b}$ & $3.06(0.41)^{a, b}$ & $3.44(0.40)^{a, b, c}$ & $3.89(0.20)^{a, b, c}$ \\
\hline \multirow[t]{4}{*}{$30^{\circ}$} & PCL intact group & $1.23(0.15)$ & $1.37(0.17)$ & 1.44(0.18) & $1.61(0.16)$ & $1.77(0.16)$ \\
\hline & ALB rupture group & $3.24(0.21)^{\mathrm{a}}$ & $3.63(0.25)^{a}$ & $3.96(0.19)^{\mathrm{a}}$ & $4.06(0.36)^{a}$ & $4.16(0.19)^{\mathrm{a} \Lambda}$ \\
\hline & PMB rupture group & $1.25(0.19)^{b}$ & $1.41(0.18)^{b}$ & $1.56(0.14)^{b}$ & $2.10(0.19)^{a, b}$ & $2.31(0.29)^{a} \mathbf{\Lambda}, b \boldsymbol{\Lambda}$ \\
\hline & PCL rupture group & $3.40(0.24)^{a, c}$ & $3.76(0.19)^{a, c}$ & $4.16(0.17)^{a, c}$ & $4.55(0.22)^{a, b, c}$ & $4.98(0.15)^{\mathrm{a} \boldsymbol{\Lambda}, \mathrm{b} \boldsymbol{\Lambda}, \mathrm{\Lambda}}$ \\
\hline \multirow[t]{4}{*}{$60^{\circ}$} & PCL intact group & $1.26(0.15)$ & $1.34(0.12)$ & $1.53(0.16)$ & $1.68(0.13)$ & $1.86(0.12)$ \\
\hline & ALB rupture group & $3.72(0.26)^{a}$ & $4.14(0.22)^{a} \boldsymbol{\Lambda}$ & $4.41(0.17)^{a}$ & $4.64(0.24)^{a}$ & $5.09(0.21)^{a}$ \\
\hline & PMB rupture group & $1.36(0.27)^{b}$ & $1.47(0.12)^{b} \boldsymbol{\Delta}$ & $1.60(0.19)^{b}$ & $2.36(0.21)^{a, b}$ & $2.59(0.19)^{a, b}$ \\
\hline & $\mathrm{PCL}$ rupture group & $3.95(0.23)^{a, c}$ & $4.26(0.16)^{\mathrm{a} \boldsymbol{\Lambda}, c \boldsymbol{\Lambda}}$ & $4.59(0.22)^{a, c}$ & $5.11(0.30)^{a, b, c}$ & $5.87(0.24)^{a, b, c}$ \\
\hline \multirow[t]{4}{*}{$90^{\circ}$} & PCL intact group & $1.12(0.11)$ & $1.40(0.16)$ & $1.66(0.16)$ & $1.76(0.16)$ & $2.02(0.16)$ \\
\hline & ALB rupture group & $3.60(0.16)^{a} \boldsymbol{\Lambda}$ & $4.03(0.16)^{a}$ & $4.23(0.22)^{a}$ & $4.49(0.20)^{\mathrm{a}}$ & $4.92(0.20)^{\mathrm{a}}$ \\
\hline & PMB rupture group & $2.21(0.28)^{\mathrm{a} \boldsymbol{\Lambda}, \mathrm{b} \boldsymbol{\Lambda}}$ & $2.42(0.28)^{a, b}$ & $3.06(0.28)^{a, b}$ & $3.64(0.28)^{a, b}$ & $4.08(0.29)^{a, b}$ \\
\hline & PCL rupture group & $4.64(0.24)^{\mathrm{a} \boldsymbol{\Lambda}, \mathrm{b} \boldsymbol{\Lambda}, \mathrm{C} \boldsymbol{\Lambda}}$ & $4.98(0.24)^{a, b, c}$ & $5.21(0.25)^{a, b, c}$ & $5.47(0.22)^{a, b, c}$ & $5.97(0.15)^{a, b, c}$ \\
\hline
\end{tabular}

$P C L$ posterior cruciate ligament, $A L B$ anterolateral band, $P M B$ posteromedial band

$\triangle$ Dunnett-T3 test

a $P<0.05$ compared with $P C L$ intact

${ }^{\mathrm{b}} P<0.05$ compared with ALB rupture

${ }^{c} P<0.05$ compared with $\mathrm{PMB}$ rupture

The results at $60^{\circ}$ of flexion were similar to $30^{\circ}$. In comparison with the PCL intact group, the displacement of the ALB rupture and PCL complete rupture groups was higher under all loads $(P<0.05)$. The displacement of the PMB rupture group higher under the load of $800 \mathrm{~N}$ and $1000 \mathrm{~N}(P<0.05)$. The displacement of the $\mathrm{PMB}$ rupture group differed significantly from that of the ALB rupture group under all loads, and the displacement of the PCL rupture group differed significantly from the ALB rupture group under the load of $800 \mathrm{~N}$ and $1000 \mathrm{~N}(P<0.05)$. In comparison with the PMB rupture group, the displacement showed a significant increase in the PCL complete rupture under all loads $(P<0.05)$.

At $90^{\circ}$ of flexion, mutual comparisons of the displacement among the various groups revealed statistically significant differences under all loads $(P<0.05)$. The correlation of the displacement of the medical meniscus in each group increased in the following sequence: PCL complete rupture group > ALB rupture group > PMB rupture group $>$ PCL intact group.

\section{Discussion}

The menisci are indispensable structures of the knee that protect the articular surfaces of the knee from axial loads [18]. Boxheimer demonstrated that most obvious medial meniscus movement is detected in the anterior horn when the knee in supine and externally rotated at $90^{\circ}$ flexion position, through monitoring meniscal movement in asymptomatic knees via a MRI scanner [19]. Meniscal subluxation is generally defined as the distance between the peripheral border of the meniscus and the edge of the tibial plateau over $3.0 \mathrm{~mm}$ [20], and this criterion was applied in the present study. It was found that the medial meniscus displacement increased significantly increased along with the change of loads and flexion angles. An intact PCL restricted meniscal movement such that medial meniscus displacement fluctuated between $1.0 \mathrm{~mm}$ and $2.0 \mathrm{~mm}$, which falls within the range of physiological movement $(<3.0 \mathrm{~mm})$. Although the displacement did not vary greatly with the change of loads and flexion angles when the PCL was intact, it increased significantly under the conditions in which the PCL was completely or even partially ruptured.

The results suggested that the medial meniscus radial displacement at $0^{\circ}$ of knee flexion after ALB rupture $(1.25-2.31 \mathrm{~mm})$ remained a physiological movement, while it increased significantly after PMB rupture $(\geq 3.0 \mathrm{~mm})$, indicating instability of the knee joint, or even subluxation. It was inferred that ALB is secondary to $\mathrm{PMB}$ in maintaining the stability at $0^{\circ}$ of flexion. When the knee was flexed to $30^{\circ}$ and $60^{\circ}$ under a load less than $600 \mathrm{~N}$, no significant difference in displacement was observed between the PMB rupture and PCL 
intact groups. Therefore, the displacement in both groups was still considered physiological movement. However, the displacement $(>3.0 \mathrm{~mm})$ occurred in the ALB rupture and PCL complete rupture groups under the same load and flexion angle. Such results indicated that PMB is secondary to ALB in maintaining the stability at $30^{\circ}$ and $60^{\circ}$ of flexion. However, no complete linear relationship between loading and medial meniscus displacement was found when either the ALB or the PMB was ruptured. An apparent slope change was noted in the displacement curve when the load was over $600 \mathrm{~N}$, suggesting that fiber bundles had the ability of selfadjustment within a certain range of loads when the PCL was incompletely ruptured. This compensatory mechanism redistributed stress and reduced the displacement of the meniscus. However, when the load increased beyond a threshold value, the meniscus could cause obvious signs of knee joint instability or even subluxation. When flexed to $90^{\circ}$, the meniscus displacement differed significantly within the intra-group comparisons of all groups $(P<0.05)$. Subluxation occurred at $600 \mathrm{~N}$ and above in the PMB rupture group, and at $200 \mathrm{~N}$ and above in the ALB rupture and PCL complete rupture groups. Therefore, both ALB and PMB, especially the former, are associated with knee joint stability at $90^{\circ}$ of flexion.

As the normal position of the meniscus is a key factor in load bearing and transmission, abnormal menisci are a critical cause of articular cartilage degeneration, and can result in the progression of OA in the knee [21]. Meniscus subluxation exerts the similar effect to a partial or complete resection of the meniscus, which can reduce the contact area of the tibial-femoral joint, increase the joint strain and accelerate the development of OA [22]. Kenny found that knee joints with radial displacement of the medial meniscus observed from MRI were also have a radiographic Fairbank's sign, a feature of meniscectomy-induced OA, evident in X-rays [3]. Meniscal subluxation has been previously proved to be a cause of joint space narrowing [23, 24], leading to the conclusion that early knee OA may be attributed to meniscal subluxation, instead of the thinning of the articular cartilage [25]. Sugita observed well-preserved medial menisci in cases of severe varus OA patients, and inferred that the menisci were saved from radial displacement, which precedes the narrowing of the medial joint space and leads to the progression of varus OA [26]. Roubille found more loss of cartilage volume in the lateral plateau in patients with meniscal subluxation. This finding indicated that the meniscal extrusion in the medial compartment can not only cause loss of cartilage volume in the ipsilateral compartment, and affect the contralateral side; meanwhile, it may also serve as a trigger of pathways causing cartilage damage throughout the whole joint [21]. PCL rupture may result in abnormal strain and disrupt the normal creep kinetics of the meniscus, leading to a series of physical problems, including the malnutrition of the meniscal tissue, the degeneration of the meniscus, the loss of hoop stress resistance, the meniscus extrusion, the decrease in loadbearing ability, the knee joint instability, articular cartilage damage and $\mathrm{OA}$ [18]. On the whole, meniscal subluxation may serve as a stimulating factor during the development of OA. A stable knee joint can effectively prevent meniscus subluxation and articular cartilage degeneration.

The present study is subject to several limitations. First, the study had a relatively small sample size. In order to draw more definitive conclusions, larger-scale investigations needs to be carried out. Second, the specimens were collected from young donors who might not be able to represent the status of all population especially the senior people. Third, it is impossible to simulate complex loading conditions such as tibial rotation and mediolateral forces in cadaveric knees. Fourth, the same knees were used during sequential testing, which may lead to fatigue failure of the surrounding secondary restraints. Therefore, $10 \mathrm{~min}$ interval was set during the testing to restore to the elasticity of the specimens. Finally, the dissection of the articular capsule and the adjacent soft tissue may change the normal physiological structure, which leads to errors in measurement. Thus a longitudinal incision was adopted to minimize the effect on the knee joint stability.

\section{Conclusions}

The present study indicates that either partial or complete rupture of the PCL can increase the radial displacement of the medial meniscus, which may explain the degenerative changes occuring in the medial meniscus upon PCL injury. Therefore, early reestablishment of the PCL is necessary for maintaining the stability of the knee joint after PCL injury.

\begin{abstract}
Abbreviations
ALB: Anterolateral bundle; MRI: Magnetic resonance imaging; NS: Normal saline; OA: Osteoarthritis; PCL: Posterior cruciate ligament rupture; PMB: Posteromedial bundle; SNK-q test: Student-Newman-Keuls test

Acknowledgements

Not applicable.

Funding

This work was supported by the the Open-End Fund for the Valuable and Precision Instruments of Central South University (CSUZC201639), China Scholarship Council (student ID: 201,606,370,164), and the Hunan Provincial Innovation Foundation for Postgraduate (CX2016B060).
\end{abstract}

Availability of data and materials

All data generated or analysed during this study are included in this published article. 


\section{Authors' contributions}

CZ study design, performed the experiment, data analyses, manuscript preparation. ZHD performed the experiment, data collection and analyses, manuscript preparation. WL data collection and analyses. WFX data collection and analyses. YHH data collection and analyses. ZL data collection and analyses. KHL study design, data analyses, manuscript preparation. $\mathrm{HBH}$ study design, data analyses, manuscript preparation. All authors read and approved the final manuscript.

\section{Ethics approval and consent to participate}

Our experiment was approved by the Medical Ethics Committee of Xiangya Hospital, Central South University (Grant number: 201,212,062).

Donors' relatives were informed of the purpose of our research and signed a consent form for experiment.

\section{Consent for publication}

Not applicable.

\section{Competing interests}

The authors declare that they have no competing interests.

\section{Publisher's Note}

Springer Nature remains neutral with regard to jurisdictional claims in published maps and institutional affiliations.

Received: 21 September 2016 Accepted: 27 June 2017

Published online: 11 July 2017

\section{References}

1. Rennie WJ, Finlay DB. Meniscal extrusion in young athletes: associated knee joint abnormalities. AJR Am J Roentgenol. 2006;186(3):791-4.

2. Gao SG, Zhang C, Zhao RB, Liao Z, Li YS, Yu F, et al. Effect of partial and complete posterior cruciate ligament transection on medial meniscus: a biomechanical evaluation in a cadaveric model. Indian J Orthop. 2013;47(5):493-9.

3. Kenny C. Radial displacement of the medial meniscus and Fairbank's signs. Clin Orthop Relat Res. 1997;339:163-73.

4. Breitenseher MJ, Trattnig S, Dobrocky I, Kukla C, Nehrer S, Steiner E, et al. MR imaging of meniscal subluxation in the knee. Acta Radiol. 1997;38(5):876-9.

5. Verdonk P, Depaepe Y, Desmyter S, De Muynck M, Almqvist KF, Verstraete K, et al. Normal and transplanted lateral knee menisci: evaluation of extrusion using magnetic resonance imaging and ultrasound. Knee Surg Sports Traumatol Arthrosc. 2004;12(5):411-9.

6. Puig L, Monllau JC, Corrales M, Pelfort X, Melendo E, Caceres E. Factors affecting meniscal extrusion: correlation with MRI, clinical, and arthroscopic findings. Knee Surg Sports Traumatol Arthrosc. 2006;14(4):394-8.

7. Sharma L, Eckstein F, Song J, Guermazi A, Prasad P, Kapoor D, et al. Relationship of meniscal damage, meniscal extrusion, malalignment, and joint laxity to subsequent cartilage loss in osteoarthritic knees. Arthritis Rheum. 2008:58(6):1716-26.

8. Kawaguchi K, Enokida M, Otsuki R, Teshima R. Ultrasonographic evaluation of medial radial displacement of the medial meniscus in knee osteoarthritis. Arthritis Rheum. 2012;64(1):173-80.

9. Lee DH, Lee BS, Kim JM, Yang KS, Cha EJ, Park JH, et al. Predictors of degenerative medial meniscus extrusion: radial component and knee osteoarthritis. Knee Surg Sports Traumatol Arthrosc. 2011;19(2):222-9.

10. Yanagisawa S, Ohsawa T, Saito K, Kobayashi T, Tajika T, Yamamoto A, et al. Population-based study of the relationship between medial meniscus radial displacement, determined by use of ultrasound screening, and knee pain. J Orthop Sci. 2014;19(6):954-8.

11. Fanelli GC, Beck JD, Edson CJ. Current concepts review: the posterior cruciate ligament. J Knee Surg. 2010;23(2):61-72.

12. Hoher J, Vogrin TM, Woo SL, Carlin GJ, Aroen A, Harner CD. In situ forces in the human posterior cruciate ligament in response to muscle loads: a cadaveric study. J Orthop Res. 1999;17(5):763-8.

13. Skyhar MJ, Warren RF, Ortiz GJ, Schwartz E, Otis JC. The effects of sectioning of the posterior cruciate ligament and the posterolateral complex on the articular contact pressures within the knee. J Bone Joint Surg Am. 1993;75(5):694-9.

14. Levy IM, Torzilli PA, Warren RF. The effect of medial meniscectomy on anterior-posterior motion of the knee. J Bone Joint Surg Am. 1982;64(6):883-8.

15. Kohn D. Arthroscopy in acute injuries of anterior cruciate-deficient knees: fresh and old intraarticular lesions. Arthroscopy. 1986;2(2):98-102.
16. Wickiewicz TL. Meniscal injuries in the cruciate-deficient knee. Clin Sports Med. 1990;9(3):681-94.

17. Lei $P$, Sun R, Hu Y, Li K, Liao Z. Effect of posterior cruciate ligament rupture on the radial displacement of lateral meniscus. Clin Biomech (Bristol, Avon). 2015;30(5):448-53.

18. Marzo JM, Gurske-DePerio J. Effects of medial meniscus posterior horn avulsion and repair on tibiofemoral contact area and peak contact pressure with clinical implications. Am J Sports Med. 2009;37(1):124-9.

19. Boxheimer L, Lutz AM, Treiber K, Goepfert K, Crook DW, Marincek B, et al. $M R$ imaging of the knee: position related changes of the menisci in asymptomatic volunteers. Investig Radiol. 2004;39(5):254-63.

20. Magee T. MR findings of meniscal extrusion correlated with arthroscopy. J Magn Reson Imaging. 2008;28(2):466-70.

21. Roubille C, Martel-Pelletier J, Raynauld JP, Abram F, Dorais M, Delorme P, et al. Meniscal extrusion promotes knee osteoarthritis structural progression: protective effect of strontium ranelate treatment in a phase III clinical trial. Arthritis Res Ther. 2015;17:82.

22. Spilker RI, Donzelli PS. Knee meniscus: basic and clinical foundations. New York: Raven Press; 1992. p. 91-105.

23. Gale DR, Chaisson CE, Totterman SM, Schwartz RK, Gale ME, Felson D. Meniscal subluxation: association with osteoarthritis and joint space narrowing. Osteoarthr Cartil. 1999:7(6):526-32.

24. Bennett LD, Buckland-Wright JC. Meniscal and articular cartilage changes in knee osteoarthritis: a cross-sectional double-contrast macroradiographic study. Rheumatology (Oxford). 2002;41(8):917-23.

25. Adams JG, McAlindon T, Dimasi M, Carey J, Eustace S. Contribution of meniscal extrusion and cartilage loss to joint space narrowing in osteoarthritis. Clin Radiol. 1999;54(8):502-6.

26. Sugita T, Kawamata T, Ohnuma M, Yoshizumi Y, Sato K. Radial displacement of the medial meniscus in varus osteoarthritis of the knee. Clin Orthop Relat Res. 2001:387:171-7.

\section{Submit your next manuscript to BioMed Central and we will help you at every step:}

- We accept pre-submission inquiries

- Our selector tool helps you to find the most relevant journal

- We provide round the clock customer support

- Convenient online submission

- Thorough peer review

- Inclusion in PubMed and all major indexing services

- Maximum visibility for your research

Submit your manuscript at www.biomedcentral.com/submit
Biomed Central 